\title{
BMJ Open Identification and prevalence of adverse drug events caused by potentially inappropriate medication in homebound elderly patients: a retrospective study using a nationwide survey in Japan
}

\author{
Mitsuko Onda, ${ }^{1}$ Hirohisa Imai, ${ }^{2}$ Yurina Takada, ${ }^{1}$ Shingo Fujii, ${ }^{1}$ Takako Shono, ${ }^{1}$ \\ Yoko Nanaumi ${ }^{3}$
}

To cite: Onda M, Imai H, Takada $Y$, et al. Identification and prevalence of adverse drug events caused by potentially inappropriate medication in homebound elderly patients:

a retrospective study using a nationwide survey in Japan. BMJ Open 2015;5:e007581. doi:10.1136/bmjopen-2015007581

- Prepublication history for this paper is available online. To view these files please visit the journal online (http://dx.doi.org/10.1136/ bmjopen-2015-007581).

Received 4 January 2015 Revised 25 May 2015 Accepted 22 June 2015

CrossMark

For numbered affiliations see end of article.

Correspondence to Dr Hirohisa Imai; imaihiro@ niph.go.jp

\section{ABSTRACT}

Objectives: A nationwide large-scale survey was conducted to identify the prevalence and causal medications of adverse drug events (ADEs) that are caused by potentially inappropriate medications (PIMs) given to homebound elderly patients, factors associated with $A D E s$, and measures taken by pharmacists to manage ADEs and their effects on ADEs.

Settings: A questionnaire was mailed to 3321 pharmacies nationwide. It asked about the details of PIMs and ADEs of up to 5 patients for whom home visits were provided by a pharmacist. Questionnaire forms were filled in by pharmacists who visited the patients.

Design and participants: Between 23 January and 13 February 2013, comprehensive assessment forms were sent to 3321 pharmacies. Data collected from 1890 pharmacies including data of 4815 patients were analysed and 28 patients of unknown sex were excluded. Their average age was 82.7 years. PIMs were identified based on the 2003 Beers Criteria Japan.

Results: There were 600 patients who did not provide valid answers regarding the medications. In the remaining 4243 patients, one or more medications that were considered to be PIMs had been prescribed to $48.4 \%$ of patients. PIM-induced ADEs were found in $8 \%$ of these patients by pharmacists during home visits. The top ADE-inducing medications were strong anticholinergic antihistamines, benzodiazepines, sulpiride and digoxin. The most common ADEs associated with benzodiazepines were frequent lightheadedness, somnolence and sleepiness, which increase the risk of falls and subsequent fractures in elderly patients. The following factors associated with ADEs were identified: sex, pharmacist awareness of prescription issues, frequency of visits and time spent at patients' homes, and the frequency of detailed checks for patient adverse reactions by pharmacists.

Conclusions: The PIM prevalence associated with home healthcare in Japan was relatively high, as reported in previous studies. The present study suggests that

\section{Strengths and limitations of this study}

- The incidence of potentially inappropriate medication (PIM) use and associated adverse drug events (ADEs) were evaluated, independent of the views of medical care providers, by conducting a nationwide survey of pharmacists who were providing services to homebound elderly patients.

- PIMs were prescribed to $48.4 \%$ of patients, which is higher than the $2.9-38.5 \%$ in previous studies based on Beers Criteria 2003, suggesting that our approach identified PIMs that might have been previously overlooked.

- ADEs were experienced in $8 \%$ of patients who were prescribed PIM, and were mostly related to the central nervous system, which could potentially lead to more serious conditions. This highlights the importance of vigilance for PIM.

- Responses of visiting pharmacists to ADEs were helpful in preventing serious situations. Home visits by pharmacists should be further encouraged.

- Despite the relatively low rate of response $(56.9 \%)$ to the initial inquiry, and the reporting means that were rather open to interpretation by the pharmacist on site, the present study provides important insights in reducing the use of PIMs and associated ADEs.

pharmacists could reduce the incidence of PIMs and consequent ADEs.

\section{INTRODUCTION}

There are numerous reports on the evaluation of prescriptions for elderly patients, 
based on the Beers Criteria. A systematic review of 19 studies-14 of which used the Beers Criteria (the 2003 version was used in 11 papers, the 1997 version was used in 2 papers and the 1991 version was used in 1 paper)on elderly patients in the primary care setting revealed that the median rate of inappropriate medication prescription was $20.5 \%$ among elderly patients 65 years of age or older, and that diphenhydramine and amitriptyline were most commonly associated with high-risk adverse drug events (ADEs), while propoxyphene and doxazosin were often associated with low-risk ADEs. ${ }^{1}$

A study of Swiss outpatients based on data collected from a health insurance company revealed that the prevalence of potentially inappropriate medication (PIMs) according to 2003 Beers Criteria or PRISCUS list was $21 \%$ in patients 65 years of age or older, ${ }^{2}$ while a study of 2707 homebound elderly patients receiving home care in eight European countries revealed that the average percentage of PIM, according to all expert panel criteria for community-living elderly persons (Beers and McLeod) was $19.8 \% .^{3}$ ADEs caused by PIMs in elderly patients are serious drug-related issues.

Japan is the most rapidly ageing country among industrialised nations. However, sufficient medical care of elderly patients and control of its costs are common issues that are shared by many countries. The Japanese government is promoting home healthcare as a national policy to improve quality of life and control inpatient medical costs associated with the care of elderly patients. Several studies have already found clinical and economic advantages of home healthcare over inpatient healthcare. ${ }^{4-8}$ An understanding of the prevalence of PIM-induced ADEs and factors associated with ADEs in elderly patients in home healthcare settings is necessary for establishing safe pharmacotherapy and formulating policy for optimising medical costs associated with home healthcare in the future. To date, most prevalence studies have been small-scale studies in which biases are difficult to avoid and therefore lack sufficient credibility or validity. Large-scale studies are needed to obtain accurate and more detailed information.

The objective of this study was to conduct a nationwide, large-scale survey to shed light on the occurrence of PIM-induced ADEs in homebound elderly patients receiving home healthcare services, and to identify the drugs that cause such ADEs, factors associated with ADEs, measures taken by pharmacists to manage such ADEs and the effectiveness of such measures.

\section{METHODS}

Patients

First, we conducted a screening survey to identify pharmacists who routinely provide home visit services to elderly patients, by using a questionnaire that was inserted in selected issues of the Journal of the Japan Pharmaceutical Association. Members of the Association were asked to send a single response (per pharmacy) via
FAX, and 3321 pharmacies were identified as providers of home visit services. A second questionnaire was mailed to those pharmacies, which was filled and mailed back by a pharmacist who represented their pharmacy between 23 January and 13 February 2013. On the basis of the results of a pilot study that was conducted prior to the present study, which had indicated that each pharmacy provides home visit services to a maximum of five patients per month, ${ }^{9}$ we asked the pharmacies to provide details of up to five patients who were recipients of their home visit service (excluding cases of medication delivery only), regardless of the presence of a possible PIM. When a pharmacy provided home visit services to more than five patients, the pharmacist was asked to describe the most recent five home visit cases. Requested patient information included: a physician's order for the home visit (with a summary of the patient's medical conditions), records of home visits and drug management.

\section{Data collection}

The following variables were studied: patient characteristics (sex, age, primary disease (defined as disease that had the most impact on the general condition of the patient), living arrangement, family composition); number of medications that were being taken; whether prescribed medication included those in the Beers Criteria list (PIMs); whether the pharmacist had any experience of discovering PIM-induced ADEs during visits (ADEs, if any), and details of such an episode (name of the drug (including specification), daily dose, description of ADEs, care provided by the pharmacist with physician and degree of improvement of ADEs as a result of care provided); pharmacist awareness of prescription issues (contraindications, duplication, drug interactions and unnecessary continuation of treatment); home visit service-related work load (frequency of visits, time spent at patients' homes); and the frequency of detailed pharmacist checks for ADEs that were based on test results, vitals and activity of daily living (ADL).

\section{Measurements}

The frequencies of ADEs and their characteristics described in the survey responses were assessed on the following factors based on "medications that should be avoided in elderly individuals regardless of disease or clinical condition" in the "Beers Criteria: The Japanese V.2003"10: the number and details of ADEs that occurred; the responses of pharmacists to ADEs; and the degree of improvement in ADEs as a result of such measures. ADEs were classified based on the "Geriatric Care Medication Management Manual: ADL and Medication."11

In the present study, we used the 2003 Beers Criteria in Japan, which was independently developed using the same strategy that was used to develop the original 2003 Beers Criteria with supervision by Dr Beers to better 
reflect the healthcare situation in Japan. The major differences in the Japanese version compared with the original Beers Criteria are: (1) medications that were not available at the time were excluded, (2) the upper limits for the dosage of short-acting benzodiazepines were stated and (3) four of the $\mathrm{H}_{2}$ blockers, which are commonly prescribed in Japan, that are metabolised in the liver and excreted from the kidneys, were included.

In the home healthcare system in Japan, a home visiting pharmacist is provided with patient data, as needed, by the physician in charge, and the pharmacist collects information regarding drug adherence and possible signs of adverse drug effects on each visit. Such information is then relayed to the physician, and the physician will determine whether the observed symptom is related to PIM, and if additional intervention and/or cessation of the medication is necessary.

We collected cases in which a home visiting pharmacist had documented possible symptoms of ADE after which the physician judged that the reported symptom was related to an ADE and modified the prescription as needed. The physician may have visited the patient with the pharmacist when the possible symptom(s) were identified or approximately within 1 week after the pharmacist's initial report, to further examine the situation. The physician in charge evaluated the patient's condition at her/his next visit after cessation or decrease in dose of the medication; this normally happens within 2 weeks, but the patient may be followed up for 4-8 weeks depending on the characteristics of the medication and/or the symptoms identified.

\section{Statistical analysis}

To screen for factors associated with PIM-induced ADEs, the occurrence of ADEs and the following variables were analysed by univariate analysis using the $\chi^{2}$ test: patient characteristics (sex, age, living arrangement, family composition), number of medications that were being taken, pharmacist awareness of prescription issues (contraindications, therapeutic duplication, interactions and unnecessary continuation of treatment), frequency of visits, time spent at patients' homes and the frequency of pharmacist checks for ADEs that were based on test results, vitals and ADL. Patients who had been prescribed PIMs were included in the subsequent analyses, and patients missing demographical information were excluded from the subsequent analyses. All the statistical analysis was performed using SPSS V.18.

\section{RESULTS}

Data for 5447 patients were collected from 1890 pharmacies (56.9\% response rate), of which 4843 patients were 65 years of age or older. The frequency of home visits was more than once a week in $17.3 \%$, twice a month in $63.2 \%$ and less than once a month in $19.5 \%$. The median duration of the visit was $15 \mathrm{~min}$; it was less than $10 \mathrm{~min}$ in $33 \%, 11-15 \mathrm{~min}$ in $19.4 \%, 16-20 \mathrm{~min}$ in
$16.8 \%$ and more than $20 \mathrm{~min}$ in $30.8 \%$. Patients were followed up for 26.5 months on average (median, 17 months).

\section{Patient characteristics}

The cohort of elderly patients (65 years of age or older) included 1716 men, 3099 women and 28 patients whose sex was unknown. The average age was 82.7 years (SD 7.7 years). A total of 600 patients did not provide valid information on prescribed medications and were therefore excluded, leaving 4243 patients. One or more medications that were defined as PIMs had been prescribed in $48.4 \%$ of patients (2053 patients, table 1). Signs of PIM-induced ADEs were discovered by pharmacists in $8 \%$ of patients (165 of 2053 patients who had been prescribed PIMs (table 2)) during home visits.

The proportion of women was higher. There were more male patients with cerebral infarction, chronic respiratory failure and cancer, while osteoarthritis, osteoporosis and dementia were more prevalent in female patients. A higher percentage of female patients were living independently, and a higher percentage of males were living with their spouses. The sex distribution was similar when the analysis was limited to patients who had been prescribed PIMs.

\section{PIM-induced ADEs}

Table 3 shows the details of the PIMs and the number of ADEs that had occurred. A total of 2991 PIMs had been prescribed. The top five most common medications, by drug category, were: $\mathrm{H}_{2}$ blockers (23.9\% (714/2991)); short-acting benzodiazepines (21.6\% (646/2991)); stimulant laxatives for chronic use $(12.1 \%(362 / 2991))$; long-acting benzodiazepines $(7.3 \% \quad(218 / 2991))$ and digoxin (5.3\% (159/2991)).

The top five medications frequently associated with ADEs that had been observed during home visits were: strongly anticholinergic antihistamines $(13.3 \%$ $(17 / 128))$; ultra-long-acting benzodiazepines (11.5\% $(11 / 96)$; sulpiride $(10.7 \%(13 / 122))$; short-acting benzodiazepines $(9.9 \%(61 / 646))$; and digoxin $(8.8 \%$ $(14 / 159))$.

\section{Specific details of ADEs caused by PIMs}

Among 182 ADEs associated with PIMs, as shown in table 3, specific details were retrieved in 154 cases (table 4). The top five medications associated with ADEs were: short-acting benzodiazepines (triazolam, etizolam and alprazolam), $40.9 \%$ (63 events); intermediate-acting benzodiazepines (flunitrazepam and lorazepam), $11 \%$ (17 events); long-acting benzodiazepines (diazepam and quazepam), $8.4 \%$ (13 events); sulpiride, $7.1 \%$ (11 events); and ultra-long-acting benzodiazepines (ethyl loflazepate and flutoprazepam), 6.5\% (10 events). The most common ADEs associated with short-acting, intermediate-acting and long-acting benzodiazepines were lightheadedness and sleepiness, while the most common ADE associated with ultra-long-acting 
Table 1 Characteristics of patients 65 years of age or older* $(n=4223)$

\begin{tabular}{|c|c|c|c|}
\hline \multirow[b]{2}{*}{ Variable } & \multirow[b]{2}{*}{ Classification } & \multicolumn{2}{|l|}{ Distribution (\%) } \\
\hline & & Male $(n=1495)$ & Female $(n=2728)$ \\
\hline \multirow[t]{5}{*}{ Age (years) } & $65-69$ & 9.5 & 3.6 \\
\hline & $70-79$ & 33.8 & 23.1 \\
\hline & 80-89 & 44.6 & 49.7 \\
\hline & 90-99 & 11.5 & 22.3 \\
\hline & 100 or older & 0.5 & 1.4 \\
\hline \multirow[t]{14}{*}{ Primary disease } & Circulatory disease & 12.9 & 14.0 \\
\hline & Cerebral infarction & 20.0 & 9.6 \\
\hline & Osteoarthritis & 1.5 & 4.9 \\
\hline & Fracture/osteoporosis & 1.0 & 5.6 \\
\hline & Rheumatoid arthritis & 0.7 & 2.9 \\
\hline & Amyotrophic lateral sclerosis & 1.7 & 0.7 \\
\hline & Dementia & 11.6 & 19.6 \\
\hline & Parkinson's disease & 4.3 & 3.8 \\
\hline & Other neurological disease & 3.5 & 3.0 \\
\hline & Chronic respiratory failure & 6.4 & 3.9 \\
\hline & Cancer & 6.9 & 3.0 \\
\hline & Renal failure & 1.5 & 1.0 \\
\hline & Other & 16.2 & 14.5 \\
\hline & Unknown & 11.9 & 13.5 \\
\hline \multirow[t]{4}{*}{ Living arrangement } & Home & 77.6 & 69.1 \\
\hline & Assisted-living housing & 19.3 & 25.5 \\
\hline & Special elderly nursing home & 2.4 & 4.8 \\
\hline & Unknown & 0.7 & 0.5 \\
\hline \multirow[t]{5}{*}{ Family composition } & Independent & 30.9 & 39.6 \\
\hline & Living with spouse & 32.8 & 12.7 \\
\hline & Living with family & 24.2 & 29.9 \\
\hline & Living with non-family member & 11.0 & 16.5 \\
\hline & Unknown & 1.1 & 1.4 \\
\hline
\end{tabular}

benzodiazepines was somnolence. The most common ADEs associated with sulpiride were lightheadedness, tremor and sialorrhoea. Among the medications for which maximum daily doses had been defined, 63 ADEs related to short-acting benzodiazepines and 9 ADEs related to digoxin, and were reported at doses below the defined upper daily dose limit.

For these ADEs, pharmacists had contacted a physician and had taken the following measures: discontinuation of the causative drug $(47 \%)$; dose reduction $(27.4 \%)$; change of medication $(11.6 \%)$; and other measures $(11 \%)$. It was unknown whether appropriate measures had been taken in $3 \%$ of cases. ADEs had improved in $82.3 \%$ of cases, while no improvement was reported in $14.6 \%$, and the outcome was unknown in $3.1 \%$.

\section{Univariate analysis of factors associated with ADEs}

The following factors were associated with PIM-induced ADEs: sex, pharmacist awareness of prescription issues (contraindications, therapeutic duplication, interactions and unnecessary continuation of treatment), frequency of visits and time spent at the visit, and the frequency of a detailed pharmacist check for adverse reactions (table 5).

\section{DISCUSSION}

\section{Prevalence of PIMs}

The percentage of PIM prescription in this study $(48.4 \%)$ was relatively high compared with previously reported figures. PIM ranged from $2.9 \%$ to $38.5 \%$ in 11 previous studies utilising the Beers Criteria 2003, which were analysed in a systematic review. ${ }^{1}$ Large databases in industrialised nations indicate prevalence of PIMs were $20.5 \%, 21.0 \%$ and $19.8 \%$, respectively, ${ }^{1-3}$ and studies conducted in New Zealand and Brazil found the rates were $42.7 \%, 48.0 \%$ and $49 \%$, respectively. ${ }^{12-14}$

As we had stated in Methods section, patients in the present study were reported by the participating pharmacists regardless of the presence of possible PIM. Therefore, we believe that the relatively high rate of PIM shown in the present study was not due to selection bias. The national health insurance system in Japan covers all prescription medications without limitations, and out-of-pocket expense is minimal. Therefore, prescriptions for medicines were occasionally continued for unnecessarily long periods, which may have contributed to the higher incidence of PIMs caused by polypharmacy in the present study. ${ }^{15}$

This study found that the majority of PIMs were benzodiazepines, consistent with other reported 
Table 2 Characteristics of patients 65 years of age or older who were prescribed a medication on the Beers Criteria list* $(n=2039)$

\begin{tabular}{|c|c|c|c|}
\hline \multirow[b]{2}{*}{ Variable } & \multirow[b]{2}{*}{ Classification } & \multicolumn{2}{|c|}{ Distribution (\%) } \\
\hline & & Male $(n=707)$ & Female $(n=1332)$ \\
\hline \multirow[t]{5}{*}{ Age (years) } & $65-69$ & 9.3 & 3.5 \\
\hline & 70-79 & 34.8 & 23.8 \\
\hline & 80-89 & 44.1 & 49.4 \\
\hline & 90-99 & 11.3 & 21.5 \\
\hline & 100 or older & 0.4 & 1.8 \\
\hline \multirow[t]{14}{*}{ Primary disease } & Circulatory disease & 14.6 & 14.7 \\
\hline & Cerebral infarction & 19.4 & 10.0 \\
\hline & Osteoarthritis & 2.0 & 4.7 \\
\hline & Fracture/osteoporosis & 1.0 & 6.4 \\
\hline & Rheumatoid arthritis & 0.6 & 2.6 \\
\hline & Amyotrophic lateral sclerosis & 2.0 & 0.5 \\
\hline & Dementia & 10.2 & 17.4 \\
\hline & Parkinson's disease & 3.8 & 4.1 \\
\hline & Other neurological disease & 3.3 & 3.2 \\
\hline & Chronic respiratory failure & 6.4 & 4.2 \\
\hline & Cancer & 6.1 & 2.6 \\
\hline & Renal failure & 2.1 & 1.0 \\
\hline & Other & 15.3 & 13.9 \\
\hline & Unknown & 13.4 & 14.7 \\
\hline \multirow[t]{4}{*}{ Living arrangement } & Home & 77.4 & 71.5 \\
\hline & Assisted-living housing & 19.9 & 24.1 \\
\hline & Special elderly nursing home & 2.0 & 4.0 \\
\hline & Unknown & 0.7 & 0.5 \\
\hline \multirow[t]{5}{*}{ Family composition } & Independent & 32.8 & 40.5 \\
\hline & Living with spouse & 33.7 & 12.5 \\
\hline & Living with family & 21.5 & 30.2 \\
\hline & Living with non-family member & 11.0 & 15.2 \\
\hline & Unknown & 1.0 & 1.5 \\
\hline
\end{tabular}

studies, ${ }^{2}{ }^{12-14} 16$ but there were also many cases of $\mathrm{H}_{2}$ blockers and chronic stimulant laxatives use, indicating that these medications tend to be prescribed regardless of the presence or absence of symptoms.

\section{Incidence of ADEs caused by PIMs}

The present study found that ADEs caused by PIMs had occurred in $8 \%$ of patients. The top ADE-inducing medications were strong anticholinergic antihistamines, benzodiazepines, sulpiride and digoxin. A study on the long-term effect of anticholinergic medications (which are PIMs) on bodily and cognitive functions in elderly patients reported that bodily and cognitive functions in patients treated with PIMs were significantly compromised compared with patients who did not use PIMs. ${ }^{17}$ Diphenhydramine has also been found to often cause high-risk ADEs. ${ }^{1}$ Our study discovered that strong anticholinergic medications were most frequently associated with ADEs, suggesting that caution should be advised against the use of such medications, in accordance with PIM guidelines.

Benzodiazepine-induced ADEs were discovered in $28.7 \%$ of patients. According to Fujii et al, an international comparison of psychotropic drug prescriptions revealed that the percentage of sedative hypnotic prescriptions and the number of patients using two or more concomitant hypnotic medications in Japan were greater than those in other countries. The authors attributed this to the many varieties of sedative hypnotic medications available in Japan, and to the national insurance and the medical reimbursement system that allows continued prescription and usage of such medications. ${ }^{18}$ In particular, data indicated that the number of prescriptions for anxiolytics including benzodiazepines has been increasing every year in Japan compared with the US, and is now about six times greater than that in the US. ${ }^{19}$ In the present study, which evaluated ADEs in elderly patients who were receiving home healthcare, the most common benzodiazepine-induced ADEs were lightheadedness, somnolence and sleepiness. As the typical features of indoor structures in Japan include high sills between rooms, where people can easily trip, steep stairways leading to a second story, and bathrooms with deep tubs, such ADEs could cause serious events such as falls, and result in fractures. Patients using benzodiazepines should therefore be frequently checked for symptoms such as lightheadedness, somnolence and sleepiness, and a reduction in dose or a change to another agent, for example, should be considered. 
Table 3 PIM prescriptions (in descending order) and number of ADEs by drug category

\begin{tabular}{|c|c|c|c|}
\hline Drug category* & $\begin{array}{l}\text { Number of } \\
\text { prescriptions }\end{array}$ & $\begin{array}{l}\text { Number } \\
\text { of ADEs }\end{array}$ & Per cent \\
\hline $\mathrm{H}_{2}$ blockers & 714 & 10 & 1.4 \\
\hline $\begin{array}{l}\text { Short-acting } \\
\text { benzodiazepines }\end{array}$ & 646 & 61 & 9.4 \\
\hline $\begin{array}{l}\text { Stimulant laxatives } \\
\text { (chronic use) }\end{array}$ & 362 & 18 & 5.0 \\
\hline $\begin{array}{l}\text { Long-acting } \\
\text { benzodiazepines }\end{array}$ & 218 & 16 & 7.3 \\
\hline Digoxin & 159 & 14 & 8.8 \\
\hline $\begin{array}{l}\text { Short-acting } \\
\text { nifedipine }\end{array}$ & 155 & 4 & 2.6 \\
\hline $\begin{array}{l}\text { Strongly } \\
\text { anticholinergic } \\
\text { antihistamines }\end{array}$ & 128 & 17 & 13.3 \\
\hline Ticlopidine & 123 & 5 & 4.1 \\
\hline Sulpiride & 122 & 13 & 10.7 \\
\hline Verapamil & 104 & 5 & 4.8 \\
\hline $\begin{array}{l}\text { Ultra-long-acting } \\
\text { benzodiazepines }\end{array}$ & 96 & 11 & 11.5 \\
\hline $\begin{array}{l}\text { Non-COX } \\
\text { selective NSAIDs } \\
\text { with long half-life }\end{array}$ & 94 & 3 & 3.2 \\
\hline Cimetidine & 50 & 0 & 0.0 \\
\hline Amiodarone & 20 & 2 & 10.0 \\
\hline Total & 2991 & 179 & \\
\hline \multicolumn{4}{|c|}{$\begin{array}{l}\text { *Drug category is based on Beers Criteria list. } \\
\text { ADEs, adverse drug events; COX, cyclooxygenase inhibitor; } \\
\text { NSAIDs, non-steroidal anti-inflammatory drugs; PIM, potentially } \\
\text { inappropriate medications. }\end{array}$} \\
\hline
\end{tabular}

\section{Factors associated with ADEs}

Polypharmacy, ${ }^{3} \quad 12 \quad 13 \quad 20-22$ centrally acting medications, ${ }^{2} 3121322$ anti-inflammatory drugs, ${ }^{2}$ family composition (living alone), economic status, age, presence of depression ${ }^{3}$ and the expertise of prescribing physicians, ${ }^{22}$ have been reported thus far as factors associated with PIMs. In contrast, factors that are associated with PIM-induced ADEs have rarely been studied. One hospital-based study showed that the number of medication prescribed per patient was the only factor that appeared to affect the incidence of ADEs. ${ }^{23}$ Indeed, we performed a logistic regression analysis using the presence of ADEs as a covariate, but we did not find any factor significantly affecting the outcome (data not shown).

ADEs occur more often in women. Besides the female sex, a higher number of drugs taken by women and their greater mean age compared with men could be contributory factors. Dementia, osteoarthritis and fractures/osteoporosis are more prevalent in women than in men, and multiple drugs had been prescribed for these diseases (medians of 6.0, 7.0 and 7.0 medications, respectively; data not shown), which potentially lead to a higher incidence of PIM-induced ADEs.

More frequent home visits by pharmacists would lead to more frequent checking for ADEs through examination of test results, vitals and ADL, and a greater awareness of prescription issues (contraindications, therapeutic duplication, interactions or unnecessary continuation of treatment), which might lead to more frequent discovery of ADEs. Indeed, the majority of ADEs that were noticed by the visiting pharmacist were improved as a result of measures taken by collaboration of pharmacist and physician. Even though homebound elderly patients in this study were also receiving home healthcare provided by visiting physicians and/or nurses, our study revealed that the visiting pharmacist discovered a significant number of ADEs. Therefore, the involvement of pharmacists should be increased to assist physicians and nurses in community healthcare, ${ }^{24}$ through checking the treatment adherence of homebound elderly patients and modifying prescriptions based on ADE vigilance.

\section{Limitations}

The essential findings of this study appear to be strong and compelling, despite a few minor limitations. First, the $56.9 \%$ rate of response to our main inquiry was not very high. The relatively low rate may reflect the fact that this was a large-scale, nationwide study, in which medical issues, such as the business of practice and datasharing limitations between medical care providers and pharmacists, related to location, may vary. According to the survey conducted by the Ministry of Health, Labour and Welfare of Japan that was reported in September 2013, there were 4319 pharmacies that provide home visit services nationwide, of which 3321 pharmacies $(76.9 \%)$ had participated in the present survey. Therefore, we believe that the results of our study accurately represent the prevalence of PIMs and consequent ADEs that affect elderly homebound patients receiving home visit pharmacist services, with minimum bias. Second, the degree of objectivity could be questioned, as the definition of ADEs, such as lightheadedness or somnolence, and the assessment of ADE improvement, were not determined in advance. However, the ADEs reported in this study were determined by a physician in charge based on the information provided by the pharmacist who had been following the patient for an extended period (26 months on average), along with information provided by a family member who was the main carer, therefore, proper assessment of ADEs appear to have been made. If similar studies are conducted under more stringent conditions in the future, a study design that includes third party assessments by physicians and other pharmacists using predefined criteria would be desirable.

Third, the potential economic impact of preventing ADEs was not addressed. A report showed that $44 \%$ of elderly patients who were prescribed a benzodiazepine received at least one PIM, resulting in an excess cost of $\$ 3076$ per year because of the necessity of outpatient therapy or emergency hospitalisations. ${ }^{16}$ Future studies will hopefully address such issues. 
Table 4 Details of ADEs by the type of PIM

\begin{tabular}{|c|c|c|c|}
\hline Classification* & Generic name & $\begin{array}{l}\text { Number of } \\
\text { ADEt }\end{array}$ & Details and number of ADEs \\
\hline \multirow[t]{2}{*}{$\begin{array}{l}\text { Short-acting } \\
\text { benzodiazepines }\end{array}$} & Triazolam $>0.2 \mathrm{mg}$ & 63 & $\begin{array}{l}\text { Lightheadedness: 29; insomnia: } 4 \text {; somnolence and amnesia: } 3 \text { each; delirium, tremor, } \\
\text { dependency, hallucination, fall, dysuria: } 2 \text { each }\end{array}$ \\
\hline & $\begin{array}{l}\text { Etizolam } \\
\text { Alprazolam >2 mg }\end{array}$ & & $\begin{array}{l}\text { Prolonged use of massive dose, disturbed consciousness, memory impairment, hallucination, } \\
\text { renal impairment, impaired tongue movement, insomnia, gagging, worsening of dementia, } \\
\text { somnambulism, delusions, restlessness: } 1 \text { each }\end{array}$ \\
\hline Intermediate-acting & Flunitrazepam & 17 & Lightheadedness: 6 \\
\hline benzodiazepines & Lorazepam $>3 \mathrm{mg}$ & & $\begin{array}{l}\text { Delirium, loss of motivation, oversedation, agitation, sleepiness, } \\
\text { somnolence, insomnia, terror, dementia-like symptoms, fall, dizziness on standing: } 1 \text { each }\end{array}$ \\
\hline Long-acting & Diazepam & 13 & Lightheadedness: 7 ; sleepiness: 3 \\
\hline benzodiazepines & Quazepam & & Falling out of bed, disturbed consciousness, hallucination: 1 each \\
\hline Sulpiride & Sulpiride & 11 & $\begin{array}{l}\text { Lightheadedness, tremor, sialorrhoea: } 2 \text { each, extrapyramidal symptoms, headache, anxiety, } \\
\text { constipation and walking difficulty: } 1 \text { each }\end{array}$ \\
\hline Ultra-long-acting & Ethyl loflazepate & 10 & Somnolence: 2 \\
\hline benzodiazepines & Flutoprazepam & & $\begin{array}{l}\text { Lightheadedness, oversedation, panic, hallucination, falling, sleepiness, insomnia, impaired } \\
\text { nocturnal ventilation: } 1 \text { each }\end{array}$ \\
\hline Digoxin & Digoxin & 9 & Anorexia: 4 , poisoning: 3 , nausea and hallucination: 1 each \\
\hline Ticlopidine & Ticlopidine hydrochloride & 4 & $\begin{array}{l}\text { Gastrointestinal disorder, contraindication, internal bleeding, intracerebral } \\
\text { haemorrhage: } 1 \text { each }\end{array}$ \\
\hline Barbiturates & Gabapentin & 3 & Sleepiness: 2 , lightheadedness: 1 \\
\hline $\begin{array}{l}\text { Strongly anticholinergic } \\
\text { antihistamines }\end{array}$ & $\begin{array}{l}\text { d-chlorpheniramine } \\
\text { maleate }\end{array}$ & 4 & Thirst: 2, lightheadedness and discomfort: 1 each \\
\hline $\mathrm{H}_{2}$ blockers & Famotidine & 3 & Somnolence, eczema, eruption: 1 each \\
\hline Amantadine & Amantadine hydrochloride & 3 & Lightheadedness, delirium, hallucination: 1 each \\
\hline Verapamil & Verapamil hydrochloride & 3 & Bradycardia: 2 , poorly controlled arrhythmia: 1 each \\
\hline MAO inhibitors & Selegiline & 2 & Hallucination, emotional instability: 1 each \\
\hline Amitriptyline & Amitriptyline hydrochloride & 2 & Lightheadedness, hallucination: 1 each \\
\hline Olanzapine & Olanzapine & 2 & Hypoglycaemia, ADL decreasedł: 1 each \\
\hline Amiodarone & Amiodarone hydrochloride & 1 & Tremor: 1 \\
\hline $\begin{array}{l}\text { Stimulant laxative (chronic } \\
\text { use) }\end{array}$ & Bisacodyl & 1 & Abdominal pain: 1 \\
\hline $\begin{array}{l}\text { Centrally acting muscle } \\
\text { relaxants }\end{array}$ & Tizanidine hydrochloride & 1 & Liver function test abnormal: 1 \\
\hline Doxazosin & Doxazosin mesilate & 1 & Lightheadedness: 1 \\
\hline Tetracyclic antidepressants & Maprotiline hydrochloride & 1 & Lightheadedness: 1 \\
\hline Total & & 154 & \\
\hline
\end{tabular}


Table 5 Single regression analysis of variables associated with ADEs

\begin{tabular}{|c|c|c|c|}
\hline \multirow[b]{2}{*}{ Characteristics } & \multicolumn{2}{|c|}{ ADEs \% (Number)* } & \multirow[b]{2}{*}{ p Value } \\
\hline & $\begin{array}{l}(+) \\
(n=165)\end{array}$ & $\begin{array}{l}(-) \\
(\mathrm{N}=1319)\end{array}$ & \\
\hline \multicolumn{4}{|l|}{ Sociodemographic characteristics } \\
\hline Female sex & $12.3(119)$ & $87.7(846)$ & 0.023 \\
\hline Age $\geq 75$ years & $10.9(138)$ & $89.1(1125)$ & 0.563 \\
\hline Stay at own home & $11.3(124)$ & $88.7(975)$ & 0.372 \\
\hline Live alone & $11.3(62)$ & $88.7(486)$ & 0.965 \\
\hline \multicolumn{4}{|l|}{ Drug-related characteristics } \\
\hline Polypharmacy ( $\geq 5$ drugs) & $10.6(134)$ & $89.4(1128)$ & 0.068 \\
\hline \multicolumn{4}{|l|}{ Awareness of prescription issued by pharmacist } \\
\hline Awareness of contraindications, therapeutic duplication, interactions & $21.0(17)$ & $79.0(64)$ & 0.009 \\
\hline Awareness of unnecessarily continued treatment & $20.9(18)$ & $79.1(68)$ & 0.007 \\
\hline \multicolumn{4}{|l|}{ Service-related characteristics } \\
\hline \multicolumn{4}{|l|}{ Home visiting frequency $\dagger$} \\
\hline$\leq$ Once a month & $9.4(27)$ & $90.6(259)$ & 0.045 \\
\hline About twice a month & $10.4(96)$ & $89.6(825)$ & \\
\hline$\geq$ Once a week & $15.4(41)$ & $84.6(225)$ & \\
\hline Work time $\ddagger$ ( $\geq 20 \mathrm{~min}$ ) & $14.6(109)$ & $85.4(637)$ & $<0.001$ \\
\hline \multicolumn{4}{|l|}{ Check of ADEs based on test results, vital, and ADL } \\
\hline Not performed & $6.7(28)$ & $93.3(391)$ & 0.001 \\
\hline$\leq$ Once a month & $11.6(73)$ & $88.4(554)$ & \\
\hline About twice a month & $13.7(50)$ & $86.3(315)$ & \\
\hline$\geq$ Once a week & $20.3(14)$ & $79.7(55)$ & \\
\hline $\begin{array}{l}\text { “Number of people excluding non-responders ( } \mathrm{n}=404) \text { from } 1888 . \\
\text { tFrequency of visits to patients' home. } \\
\text { fWork time at patient's home per visit. } \\
\text { ADEs, adverse drug events; ADL, activity of daily living. }\end{array}$ & & & \\
\hline
\end{tabular}

\section{Conclusion}

A large amount of data collected nationwide was used to accurately investigate the occurrence of PIM-induced ADEs in homebound elderly patients receiving home healthcare, the drugs that caused such ADEs and factors associated with ADEs. PIMs had been prescribed in $48.4 \%$ of the studied patients, and PIM-induced ADEs had occurred in $8 \%$. Of note, benzodiazepine-induced lightheadedness, somnolence and sleepiness, which increase the risk of falls and resulting fractures in elderly patients, were frequent. Measures taken by pharmacistphysician collaboration had resulted in the improvement of nearly all ADEs. The findings of this study will hopefully be useful in formulating policies for effectively preventing ADEs during home healthcare.

\section{Author affiliations}

${ }^{1}$ Clinical Laboratory of Practical Pharmacy, Osaka University of Pharmaceutical Sciences, Osaka, Japan

${ }^{2}$ National Institute of Public Health, Saitama, Japan

${ }^{3}$ Advance Pharma Research Office, Nara, Japan

Acknowledgements The contents of this article represent a portion of the results achieved through the Health and Labor Sciences Research project, entitled "Regulatory Science Integrative Research Project for Medical Drugs and Medical Devices: A Study on the Measures Regarding Active Involvement of Pharmacists in Community Healthcare" (Assignment Number H23-Medical-General-013, Study Lead: Hirohisa Imai). The authors would like to thank the authors of the above project for their support. They would also like to express our sincerest thanks to the individuals at branches of the Japan Pharmaceutical Association for their cooperation with this study.
Contributors $\mathrm{MO}$ constructed the database, performed the statistical analysis and drafted the manuscript. YT, SF, YN and TS assisted in performing the analysis and drafting of the manuscript. HI obtained the grant from Organization of the Ministry of Health, Labour and Welfare, conceived the study design, obtained the data, drafted the manuscript and superintended in drafting the manuscript. All the authors read and approved the final manuscript, are independent from funders, external and internal, had full access to all of the data (including statistical reports and tables) in the study, and can take responsibility for the integrity of the data and the accuracy of the data analysis.

Funding Ministry of Health, Labour and Welfare (grant number H23-Medical-General-013).

Competing interests None declared.

Ethics approval This study was conducted with the approval of the Research Ethics Review Board of Osaka University of Pharmaceutical Sciences.

Provenance and peer review Not commissioned; externally peer reviewed.

Data sharing statement Additional data can be accessed via the Dryad data repository at http://datadryad.org/ with the doi:10.5061/dryad.4bv57.

Open Access This is an Open Access article distributed in accordance with the Creative Commons Attribution Non Commercial (CC BY-NC 4.0) license, which permits others to distribute, remix, adapt, build upon this work noncommercially, and license their derivative works on different terms, provided the original work is properly cited and the use is non-commercial. See: http:// creativecommons.org/licenses/by-nc/4.0/

\section{REFERENCES}

1. Opondo D, Eslami S, Visscher S, et al. Inappropriateness of medication prescriptions to elderly patients in the primary care setting: a systematic review. PLoS ONE 2012;7:e43617.

2. Blozik E, Rapold R, von Overbeck J, et al. Polypharmacy and potentially inappropriate medication in the adult, community-dwelling population in Switzerland. Drugs Aging 2013;30:561-8. 
3. Fialová D, Topinková E, Gambassi G, et al., AdHOC Project Research Group. Potentially inappropriate medication use among elderly home care patients in Europe. JAMA 2005;293:1348-58.

4. Suzuki S. Promoting the System of Care-for-the-Elderly-at-home. Jap J Prim Care 1995;8:35-8.

5. Kobayashi Y, Yamaoka K, Ohi G, et al. The economic analysis of home and hospital care for terminally III patients. Jap J Public Health 1988;35:11-19.

6. Bloom BS, Priseillad K. Home and hospital cost of terminal illness Med Care 1986;18:560-4.

7. Vincent V, Thomas JD, Daniel RB, et al. Comparative cost analysis of home and hospital treatment. Prog Clin Biol Res 1986:216:155-64.

8. Dranove D. An empirical study of a hospital-based home care program. Inquiry 1985;22:59-66.

9. Onda M, Imai H, Kataoka Y, et al. A Preliminary Study about the Relationship between Workload and the Outcomes of Community Pharmacists' Home Visiting Service. Jpn J Soc Pharm 2013;32:2-7.

10. Imai $\mathrm{H}$, Beers $\mathrm{MH}$, Fick DM, et al. [The criteria of inappropriate prescribing in older patients; developing of Beers Criteria: The Japanese Version.]. J Jap Med Assoc 2008;137:84-91, (in Japanese).

11. Keiji Ueda, Japan Pharmaceutical Association ed. Koreisha care yakuzai kanri manual: ADL to yakuzai (Medication management answer book geriatric care: $A D L$ and medications). Tokyo, Japan: Yakuji Nippo Ltd, 2006.

12. Nishtala PS, Bagge ML, Campbell AJ, et al. Potentially inappropriate medicines in a cohort of community-dwelling older people in New Zealand. Geriatr Gerontol Int 2014;14:89-93.

13. Baldoni $A D$, Ayres LR, Martinez EZ, et al. Factors associated with potentially inappropriate medications use by the elderly according to Beers criteria 2003 and 2012. Int J Clin Pharm 2014:36:316-24.

14. Lee D, Martini N, Moyes S, et al. Potentially inappropriate medication use: the Beers' Criteria used among older adults with depressive symptoms. J Prim Health Care 2013;5:182-90.
15. Cannon KT, Choi MM, Zuniga MA. Potentially inappropriate medication use in elderly patients receiving home health care: a retrospective data analysis. Am J Geriatr Pharmacother 2006;4:134-43.

16. Dionne PA, Vasiliadis HM, Latimer E, et al. Economic impact of inappropriate benzodiazepine prescribing and related drug interactions among elderly persons. Psychiatr Serv 2013; 64:331-8.

17. Koyama A, Steinman M, Ensrud K, et al. Long-term cognitive and functional effects of potentially inappropriate medications in older women. J Gerontol A Biol Sci Med Sci 2014;69:423-9.

18. Fujii S, Maeda K, Shinfuku N. Survey on psychotropic drug prescription pattern in six countries and areas in East Asia. Jap J Clin Psychiatry 2003;32:629-46.

19. Murasaki M. Present situation and new prospect of psychotropic drugs in Japan-Towardthe 21th century. Jap J Clin

Psychopharmacol 2001;4:3-27.

20. Prudent $\mathrm{M}$, Dramé $\mathrm{M}$, Jolly $\mathrm{D}$, et al. Potentially inappropriate use of psychotropic medications in hospitalized elderly patients in France: cross-sectional analysis of the prospective, multicentre SAFEs cohort. Drugs Aging 2008;25:933-46.

21. Lau DT, Mercaldo ND, Harris AT, et al. Polypharmacy and potentially inappropriate medication use among community-dwelling elders with dementia. Alzheimer Dis Assoc Disord 2010;24:56-63.

22. Tanaka $\mathrm{Y}$, Onda M, Nanaumi $\mathrm{Y}$, et al. An attempt at objective evaluation of the current situation of concomitant drug use for dementia outpatients at community pharmacies. Jpn J Drug Inform 2014;15:155-64.

23. Laroche ML, Charmes JP, Nouaille $\mathrm{Y}$, et al. Is inappropriate medication use a major cause of adverse drug reactions in the elderly? Br J Clin Pharmacol 2007;63:177-86.

24. Annual Report of a Health and Labour Sciences Research project "Regulatory Science Integrative Research Project for Medical Drugs and Medical Devices: A Study on the Measures Regarding Active Involvement of Pharmacists in Community Healthcare" (Assignment No. H23-Medical-General-013, Study Lead: Hirohisa Imai). 2013. 